\title{
Landslide formation modelling and surveying of the slope in unsaturated and saturated ground conditions
}

\author{
Janusz P. Kogut ${ }^{*}$ \\ Cracow University of Technology, Faculty of Civil Engineering, Kraków, Poland
}

\begin{abstract}
The terrestrial laser scanner enables site remote sensing of the slopes in a simple and automated manner. Regular measurements with multiple scanner positioning might be applied in long term landslide monitoring. A detailed geological structural model allows for hazard assessment, and then for a slope stability assessment. Numerical model, along with the subsoil parameters, introduced into the Finite Element Method (FEM) software enables an estimation of landslide susceptibility and the possible displacements of the terrain in longer period of time, as well as, due to different loading cases. In this paper the formation of landslides and stability of the slope after the retaining structure establishment is analysed. Two analysed landslides have different origin and may be a threat even after stabilization works already maintained.
\end{abstract}

Keywords: laser scanning, numerical modelling, landslide, slope stability

\section{Introduction}

In the south of Poland where Carpathian Mountains are located, about $95 \%$ of all landslides registered in Poland have been identified and are currently being recorded. In the most susceptible regions of the Carpathians, about $40 \%$ of the area is covered by landslides or other forms of soil/rock mass movements. It is estimated that, in this region of Poland, for every square kilometer of area and for every $5 \mathrm{~km}$ of the road infrastructure network, there is one landslide, on average [1-2]. The average slope of its mountains ranges from 15 to $35 \%$, and the deep slots of the area with valleys and significant differences in height are conducive to the formation or the activation of soil/rock mass movements. Figure 1 presents the land development map from the southern part of Poland, indicating the locations, where the local landslides have been observed. These two landslides have been the subject of stability analysis described in this paper.

Landslides in southern Poland strongly threaten the existing and planned road and railway infrastructure. Hence, there is a greater need to improve the quality of substrate tests and the appropriate conclusions drawn from them. Repeatedly, construction works on the road

\footnotetext{
*Corresponding author: jkogut@pk.edu.pl
} 
substructure may violate the stability of the built-up land property and this stability violation threatens the life and health of people or property.

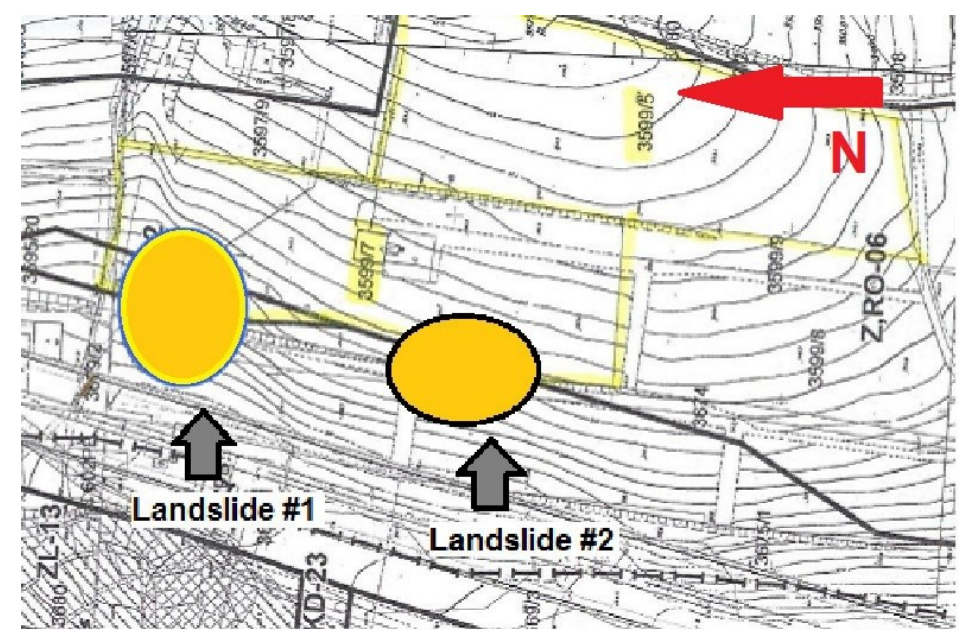

Fig. 1. Landslides formed in the analysed area (own elaboration based on local development map).

\section{FEM modelling of the slope}

\subsection{Problem formulation}

Sometimes, the designers do not refer to the design conditions in landslide terrain, neither adjusting the slope inclination, nor using strengthening of excavations of the section of the designed road. The geotechnical conditions of the area in question were determined on the basis of research of 137 boreholes made in the area of the road lane. Then, three geological and engineering cross-sections have been established. In all cross-sections, the authors of the documentation [3] described the lower layers of ground as tertiary: sandy silty clay ( $\mathrm{sasiCl}$ ) with some cobbles and boulders. In the study, there was no information about any depth researched with weathered rock basement.

But, there was a landslide map for the area, developed by the Polish Geological Institute [4]. The assumptions to the project mention that, special attention should be paid to the possibility of landslides in the area of the proposed road route. The authors of the geological and engineering documentation excluded the occurrence of landslide in the examined crosssection. No landslide survey was performed (road lane area only), but the landslide already existed and was documented with a landslide card. Unfortunately, the authors of the documentation did not thoroughly analyse the archival materials. Therefore, despite the exclusion of the possibility of landslide, contractors should pay attention to any signs of land instability [5], especially during earthworks.

It should also be added, that there is an aquifer that feeds the surrounding watercourses, as well as there is water exudation in the wetland. Therefore, it is an aquifer supplying a local stream not only with surface waters, but also the groundwater.

A terrestrial laser scanner (TLS) survey allowed us to apply the cloud map of the terrain to the numerical model. There are various slope stability analysis methods. Strength Reduction Method (SRM) is one of the non-linear method developed based on the limit equilibrium theory [6-7]. It analyses the minimum safety factor and failure behaviour using various shapes, loads, and boundary conditions. The SRM may be used to simulate the failure process without any previous assumptions and may be applied to 3D problems. The SRM 
method gradually decreases the shear strength and internal friction angle until the calculation does not converge; the obtained point is considered to be the failure point of the slope. The maximum shear strength reduction ratio, at that point, is used to calculate the minimum safety factor of the slope. Stability by SRM is achieved by weakening the soil in an elastic-plastic discrete analysis until the slope fails. The Factor of Safety is considered to be the factor by which the soil strength is to be reduced to reach failure [8].

\subsection{Numerical model of the unsaturated slope}

In the current analysis, a spatial FEM numerical model has been built to compare the behavior of the slope to a later one, already in a state of failure. Quaternary deposits recognized here are composed of silty soils - sandy silty clays, and silty clays on the layer of debris. Below it, the Magura sandstone is present, what was later on found in the documentation [3]. The groundwater table is variable, and it is located about $2.0 \mathrm{~m}$ below the ground level. The data for the numerical model, shown in Table 1, was based on the geotechnical part of the construction project, known before the commencement of works. Figure 2 shows a FEM numerical model with separate ground layers and road level. The soil surface was derived from the laser scans, which were slightly modified to the condition before significant mass movements occurred.

Table 1. Parameters used in the analyses.

\begin{tabular}{|c|c|c|c|c|c|c|c|c|}
\hline $\begin{array}{c}\text { Thickness } \\
{[\mathbf{m}]}\end{array}$ & $\begin{array}{c}\text { Depth } \\
{[\mathbf{m}]}\end{array}$ & $\begin{array}{c}\text { Soil } \\
\text { type }\end{array}$ & $\begin{array}{c}\text { Density } \\
{\left[\mathbf{g} / \mathbf{c m}^{3}\right]}\end{array}$ & $\begin{array}{c}\text { Liquid } \\
\text { limit } \\
{[\%]}\end{array}$ & $\begin{array}{c}\text { Plastic } \\
\text { limit } \\
{[\%]}\end{array}$ & $\begin{array}{c}\mathbf{I}_{\mathbf{L}} \text { [ } \\
-\mathbf{I}\end{array}$ & $\begin{array}{c}\text { Effective } \\
\text { internal } \\
\text { friction } \\
\text { angle [deg] }\end{array}$ & $\begin{array}{c}\text { Effective } \\
\text { cohesion } \\
{[\mathbf{k P a}]}\end{array}$ \\
\hline $0.0-2.6$ & 1.9 & $\mathrm{sasiCl}$ & 2.20 & 16.4 & 37.8 & 0.28 & 12.6 & 29.5 \\
\hline $2.6-3.1$ & 2.8 & $\mathrm{sasiCl}$ & 2.20 & 16.8 & 41.5 & 0.17 & 14.5 & 43.0 \\
\hline $3.1-5.0$ & 4.2 & $\mathrm{siCl}$ & 2.10 & 17.8 & 48.5 & 0.42 & 7.4 & 33.2 \\
\hline
\end{tabular}

Further calculations included checking the stability of the slope after the excavation at the toe and the assumption that the ground is unsaturated, i.e. the condition that would occur if safeguards were made in the form of escarpments and drainage ditches, without adverse weather phenomena.

The following drawings show the slope subjected to the SRM analysis. Figure 3 shows the horizontal strains of $\mathrm{E}_{\mathrm{xx}}$ in a direction perpendicular to the escarpment reflecting the loss of stability. One may clearly notice that, there is distinct horizontal strains mobilization in the left part of the slope documented as landslide \#1. Figures 3 and 4 confirm this state. The existing landslide niche is clearly outlined, especially in Figure 4, where the horizontal displacements of the FEM model of the unsaturated slope in the direction perpendicular to the slope are visible. The causes of landslide \#1 formation appear to be natural, i.e. due to gravity forces and geological conditions. 


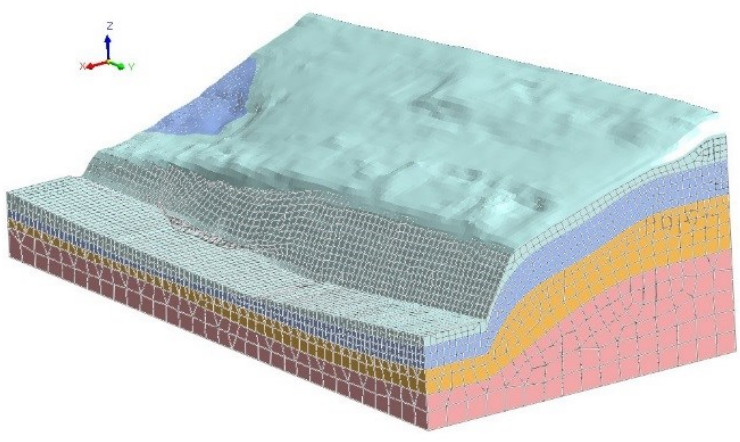

Fig. 2. 3D FEM numerical model of the slope based on the terrestrial laser scanner survey (own elaboration).

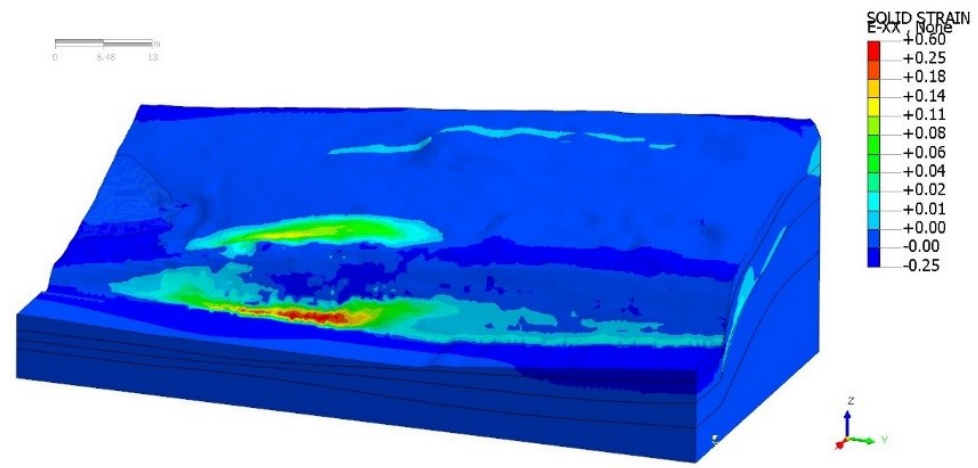

Fig. 3. The $E_{x x}$ solid strains of the unsaturated slope (own elaboration).

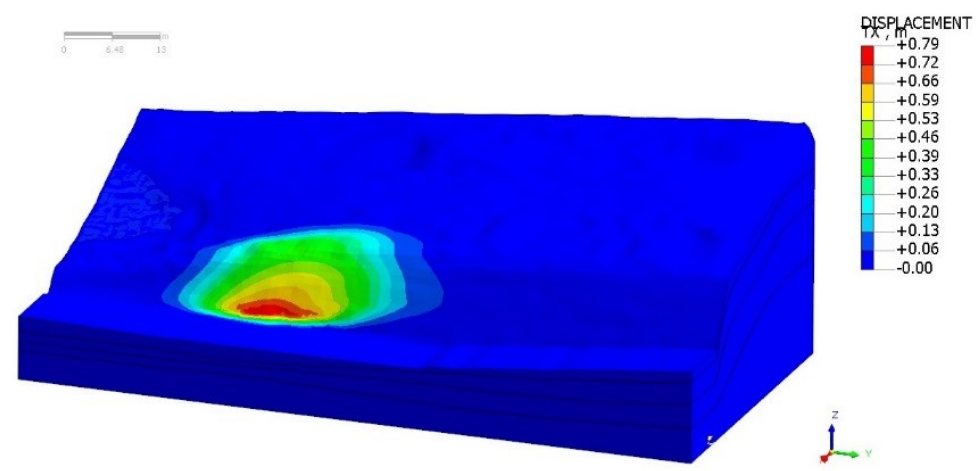

Fig. 4. The horizontal displacements of the unsaturated slope in the direction perpendicular to the slope (own elaboration). 


\subsection{Numerical model of the saturated slope}

Another case of the scarp analysed here is a situation of complete saturation of the soil that, occurred as a result of heavy rainfall. Such a situation took place during construction works and caused a long break in these works. Figure 5 shows the case of horizontal strains of $E_{x x}$ mapping the loss of stability. From the drawing, one may notice a potential slip surface developed here. Figure 6 presents horizontal displacements in a direction perpendicular to the slope and the road. From Figure 6 you may clearly see a new landslide niche, but vertical settlements do not threaten the building located above. The calculations illustrate the changes that have taken place during the construction works. Landslide \#2 has been molded due to the water saturation of the ground.

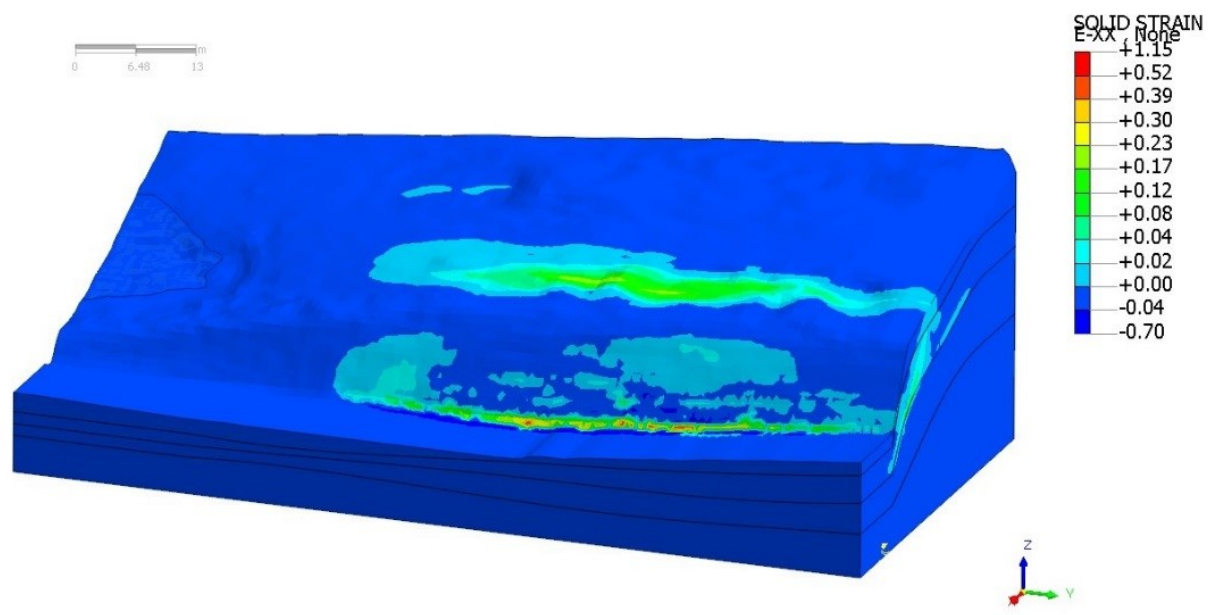

Fig. 5. The $\mathrm{E}_{\mathrm{xx}}$ solid strains of the saturated slope (own elaboration).

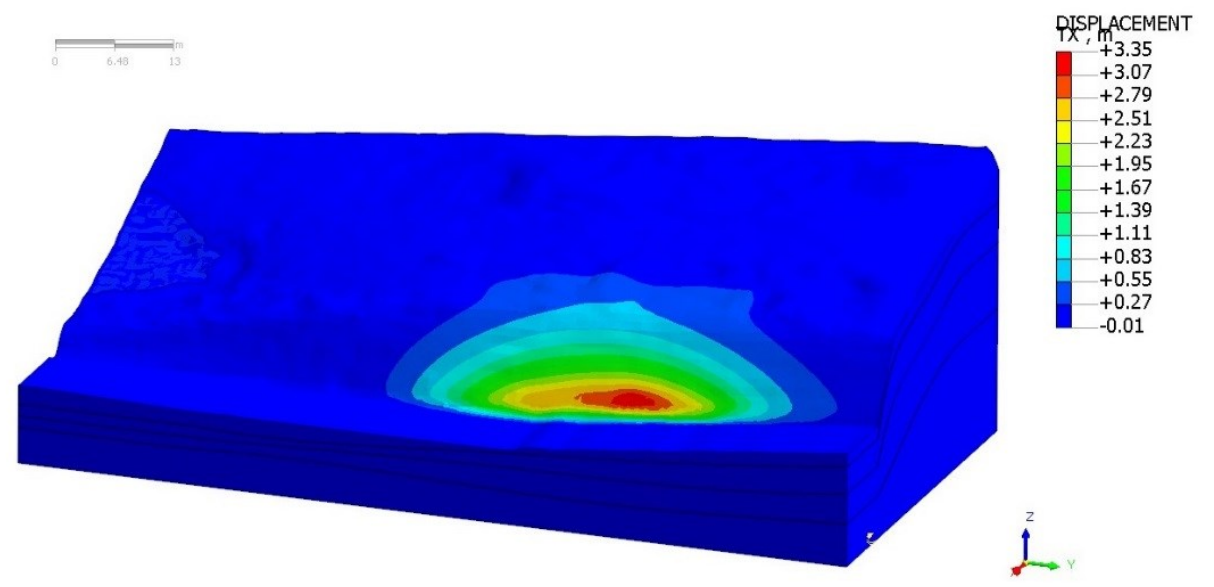

Fig. 6. The horizontal displacements of the saturated slope in the direction perpendicular to the slope (own elaboration). 


\section{Survey of the house located one the slope}

The terrestrial laser scanning, as already mentioned, is a modern terrain mapping method. The measurements are based on recording a laser beam, which is reflected from different objects. The signal, registered by the unit, is converted into an electric one and then is subjected to further digital processing. Due to the waveform analysis, and when signal reaches the receiver, the calculations are performed for the beams reflected in time intervals, for the subsequent reflecting objects. For the known light beam velocity and its run time from the source to the receiver, the distance between the scanner and the reflecting body is precisely determined. The high frequency wave emitted is by scanner is equal to $\mathrm{f}=122 \mathrm{kHz}$ [9]. The mapping of the scanned area obtained is then transformed to the Cartesian coordinates $(\mathrm{x}, \mathrm{y}, \mathrm{z})$. The data set as the form of cloud of points, creates an image of the scanned space. The measured space data is then stored for a further processing. The difficulty in the laser recording processes is the vast amount of data. Therefore, the crucial parts of the area are combined data from various measurement stands. As a part of the surveying work, a local situation and altitude map of the landslide was made using a Riegl Vz-400 terrestrial laser scanner [10]. The scanner has the option of high speed data acquisition with up to $500 \mathrm{k}$ measurements per second, with a field of view from $100^{\circ}$ to over $360^{\circ}$. The range of measurements is limited to $800 \mathrm{~m}$, with $5 \mathrm{~mm}$ accuracy and a precision of measurements about $3 \mathrm{~mm}$. The ordinates were determined using a method of direct survey in the field in the local coordinate system.

Figure 7 shows a house located on the slope in the analysed case. A terrestrial laser scan of the house is displayed in Figure 8. In fact, it is a differential model of the house prepared using the RiScan PRO software package using two consecutive scans [11-14]. The image obtained here, in the form of a cloud of points, proves that the ground movements below have almost no influence on the house located on the hill. The range of vertical deformations of the house do not exceed $2 \mathrm{~cm}$. The site is still under the investigation and the results of two consecutive scans visible in Figure 8 were performed within 12 months.

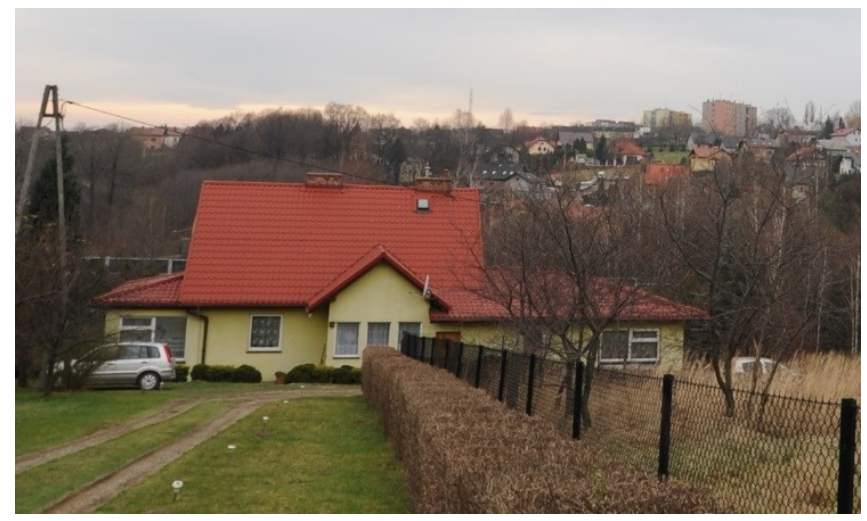

Fig. 7. The house located on the slope in the analysed case (photo by authors). 


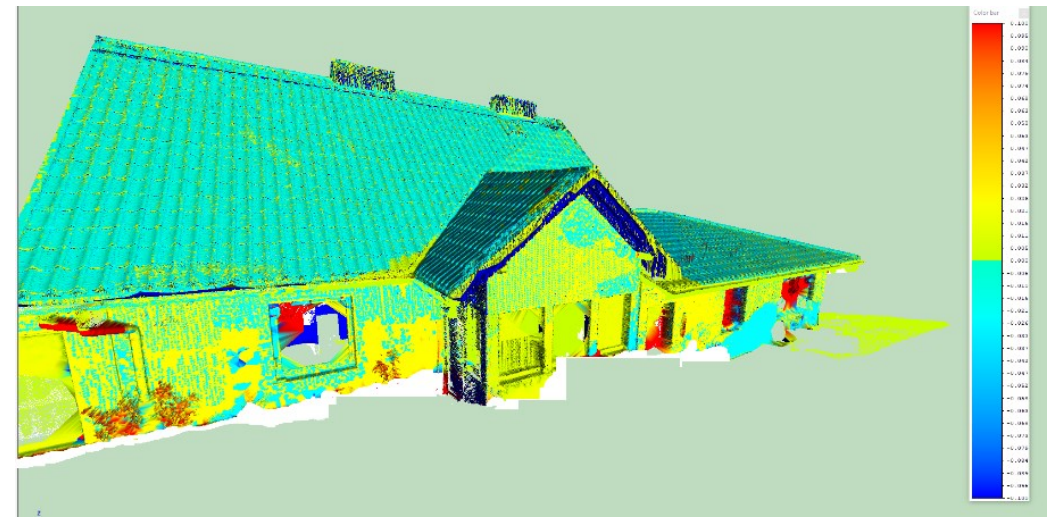

Fig. 8. Differential model of the house in the analysed case (own elaboration).

\section{Retaining structure with the noise barrier}

\subsection{TLS survey of the slope}

In the vicinity of the slope, a dual expressway was planned and built, along with a noise barrier located over the traffic lane. Therefore, earthworks were carried out involving the removal of the overburden soil and the construction of a new escarpment. Figure 9 presents the overview of the slope with the retaining structure and noise barriers. From Figure 9 one may notice that there are significant deformations of the gabion wall boxes visible. Unfortunately, gabion boxes have been filled with unstable materials, which have probably originated from the demolition of surrounding objects being in collision with the road, and these are destroyed due to poor quality - e.g. crushed remains of old concrete construction elements, which were in poor state, and due to weather conditions disintegrate. That is the reason why it is impossible to analyse the displacements of the retaining structure basing only on the laser scanning.

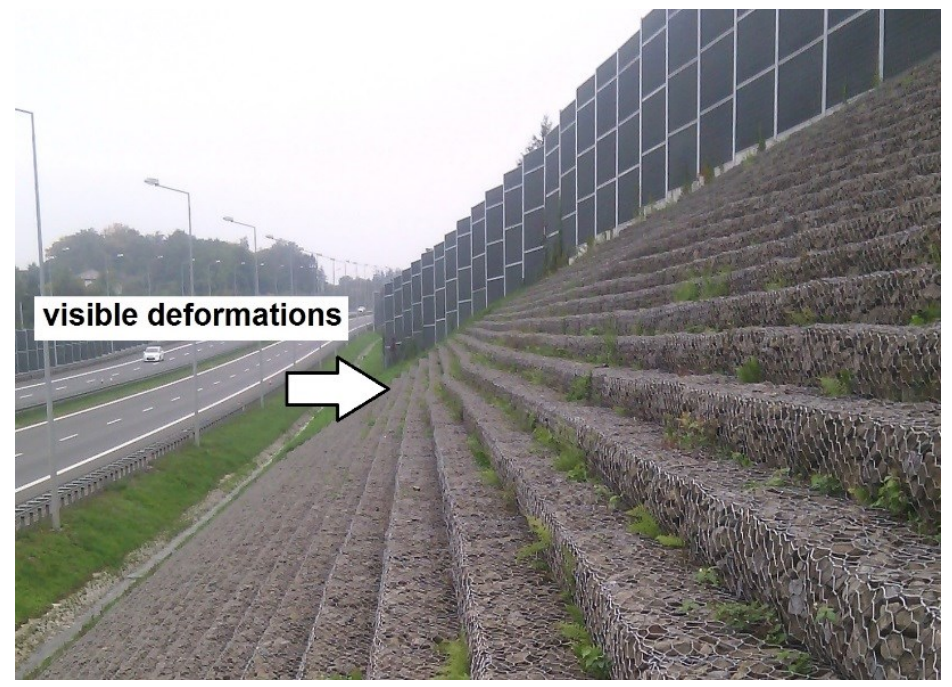

Fig. 9. Overview of the slope with retaining structure and the noise barriers (photo by authors). 
Another differential model presented in this work is the reflection of continuous acoustic screens shown in Figure 10. From the results presented here, it may be concluded that, the continuous deformation of the screens causes a slight final effect. The largest possible screen deformations are uniform and occur outside the retaining structure. The range of vertical deformations do not exceed $2 \mathrm{~cm}$.

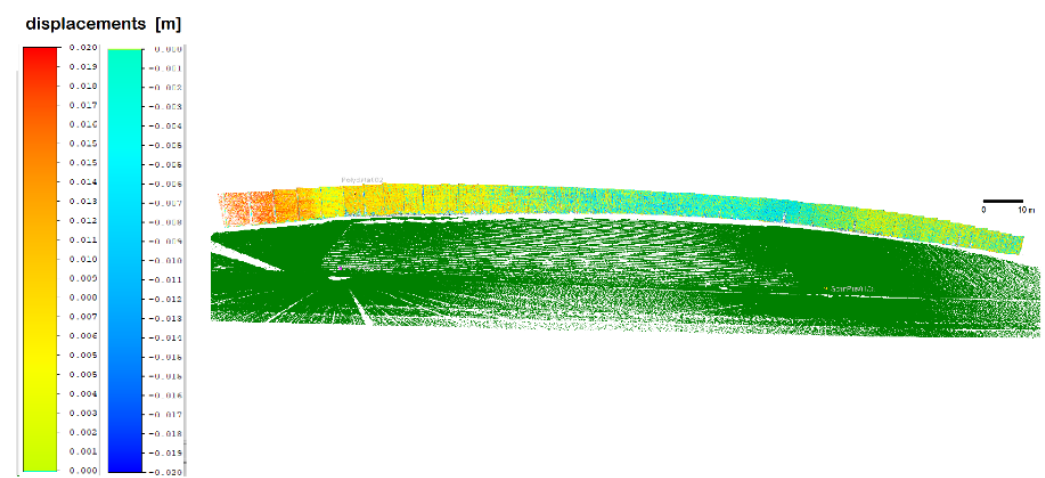

Fig. 10. Differential model of the slope with retaining structure and the noise barriers (own elaboration).

\subsection{Numerical model of the retaining structure with the noise barrier located on the slope}

Another analysed case is a situation where, there are also construction objects in the studied area located on the slope. Figure 11 shows a FEM numerical model including retaining structure, noise barrier walls and the foundation of a building located above.

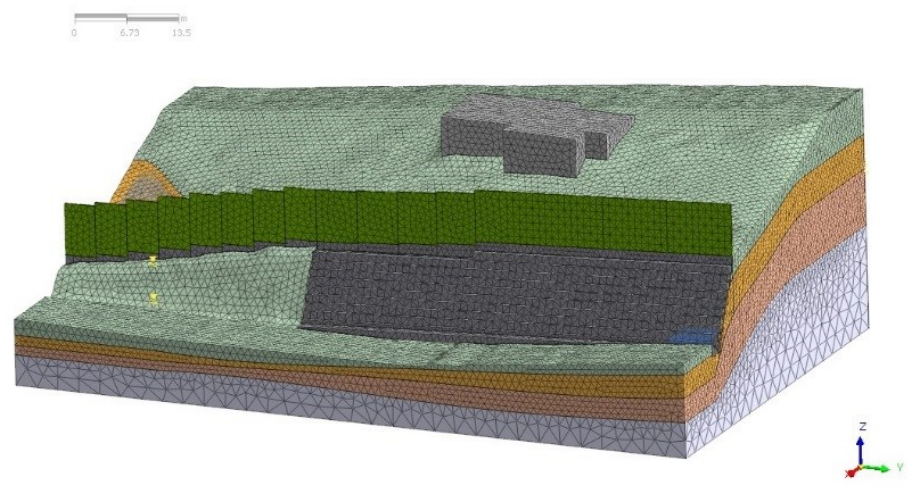

Fig. 11. 3D FEM numerical model of the slope with the noise barrier and the retaining wall including the marking of a house foundation (own elaboration).

Figure 12 displays the horizontal strains of $E_{x x}$ in a direction perpendicular to the escarpment reflecting the manner of loss of stability. We may clearly see here the problems occurring in securing the slope with gabions, shown earlier in Figure 9, and subsequently the disintegration of the aggregate in gabions. The next figure confirms that, the slope has been stabilized. It may be visible in Figure 13 that, the retaining structure balances the forces destabilizing the escarpment. It shows horizontal displacements perpendicular to the slope calculated for the existing retaining structure on the slope after the accomplishment of the 
noise barriers. Under these soil conditions, the horizontal displacements do not threaten existing facilities.
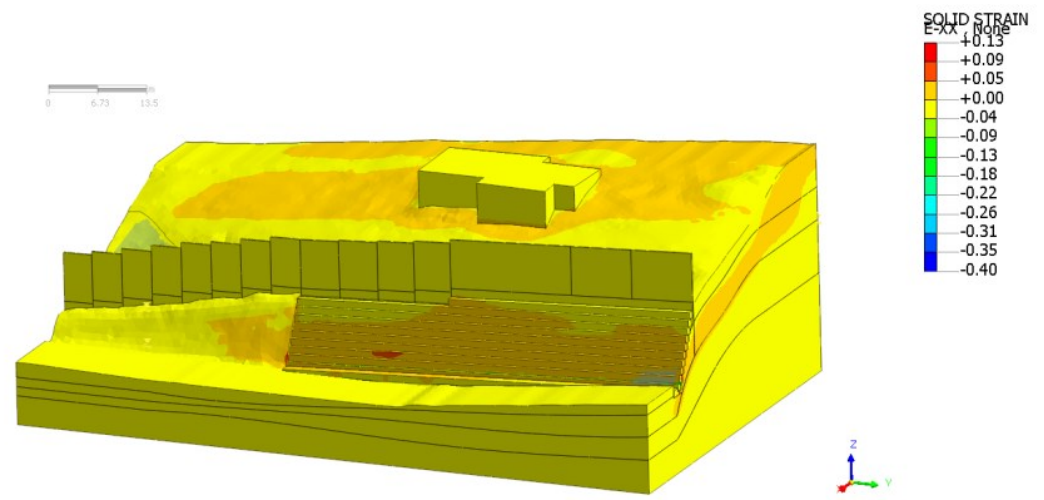

Fig. 12. The $\mathrm{E}_{\mathrm{xx}}$ solid strains of the slope with retaining structure and the noise barriers (own elaboration).

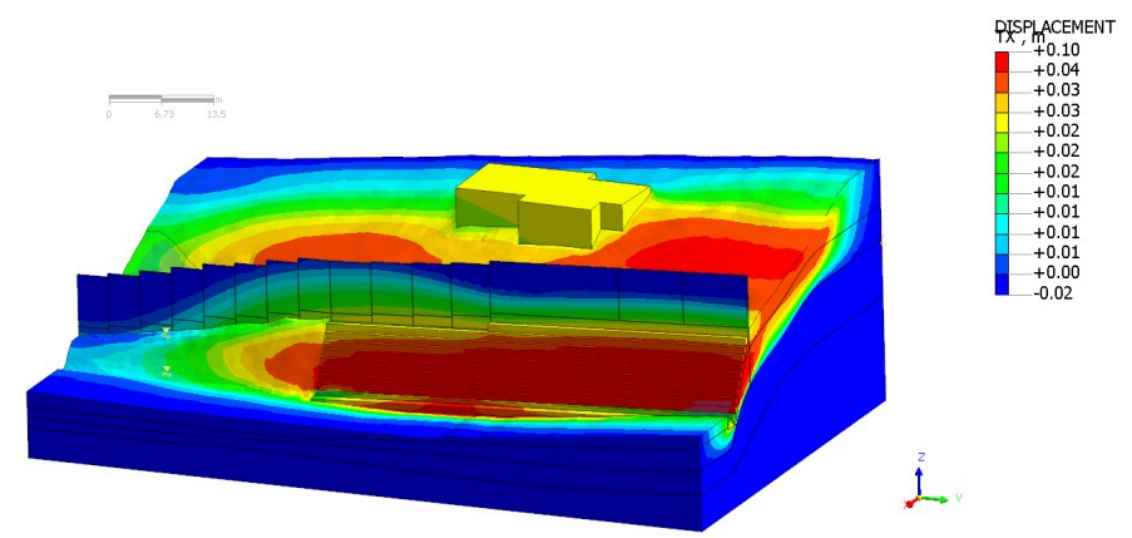

Fig. 13. The horizontal displacements of the slope with retaining structure and the noise barriers in the direction perpendicular to the slope (own elaboration).

\section{Conclusions}

This work presents the results of landslide formation modelling of the slope in unsaturated and saturated soil conditions. As it is shown here, two landslides have different origins. The laser scanning performed here proved the usefulness of the method for monitoring the deformations on the terrain surface over the potential slip surfaces. The measurement results, focused on two existing objects the retaining structure and the house above, and carried out over several months, indicated possible existence of the local landslide threat even after stabilization works. However, the deformations found are rather small and cannot be dangerous for the house located above on the slope. The terrestrial laser scanning measurements are a starting point in the discrete analyses of slope stability as visible here, illustrated by the results of FEM analyses. They may also be adapted to assess the causes of damage to buildings associated with the local landslide activity. 


\section{References}

1. D. Poprawa, W. Rączkowski, Landslides of the Carpathians, Przegląd Geologiczny 51, 8, 685-692 (2003) (in Polish)

2. L. Bober, L. Thiel, L. Zabuski, Landslide phenomena in Polish flysch Carpathians. Geological and engineering properties of selected landslides, IBW PAN Gdańsk (1997) (in Polish)

3. Ekspertyza techniczna konstrukcji oporowej trasy S69, Przedsiębiorstwo Geologiczne SA w Krakowie, Kraków (2017)

4. A. Wójcik, Karta rejestracyjna osuwiska (numer ewidencyjny 12-16-022) w miejscowości Bielsko-Biała, PIG (2005).

5. P. Harba, Z. Pilecki, Assessment of time-spatial changes of shear wave velocities of flysch formation prone to mass movements by seismic interferometry with use of ambient noise. Landslide 14 (3): 1225-1233 (2017), DOI: 1007/s10346-016-0779-2

6. D. Grifiths, P. Lane, Slope stability analysis by finite elements. Géotechnique, 49 (3), 387-403 (1999), DOI:10.1680/geot.1999.49.3.387

7. E. Pilecka, J. Kogut, D. Szwarkowski, Analysis of landslide effects along a road located in the Carpathian flysch. Open Geosciences, 10 (1): 517-531 (2018), DOI:10.1515/geo2018-0041

8. MIDAS GTS NX, Manual specifications (2016)

9. E. Pilecka, D. Szwarkowski, An application of the ground laser scanning to recognise terrain surface deformation over a shallowly located underground excavation, E3S Web of Conferences, vol. 24 (2017), DOI: 10.1051/e3sconf/20172401006

10. www.riegl.com

11. RiScan PRO Manual. Mena3D GmbH, Stuttgart, Germany (2014)

12. E. Pilecka, J. Kogut, D. Szwarkowski, Monitoring and numerical modeling of a road in landslide terrain. Civil and Environmental Engineering Reports, CEER, 28 (2): 150-163 (2018), DOI: 10.2478/ceer-2018-0026

13. I. Skrzypczak, W. Kokoszka, D. Zientek, J. Kogut, Monitoring of landslide areas with the use of contemporary methods of measuring and mapping. Civil and Environmental Engineering Reports, CEER, 24 (1): 69-82 (2017), ISSN 2080-5187.

14. J. Maciaszek, R. Gawałkiewicz, A. Szafarczyk, Geodezyjne metody badania osuwisk. Wydawnictwa AGH, Kraków (2015), ISBN 978-83-7464-778-6 